\title{
Flexible Electrospun Carbon Nanofiber/Tin(IV) Sulfide Core/Sheath Membranes for Photocatalytically Treating Chromium(VI)-Containing Wastewater
}

Yunlei Zhong, Xun Qiu, Dongyun Chen, * Najun Li, Qingfeng Xu, Hua Li, Jinghui He and Jianmei Lu*.

College of Chemistry, Chemical Engineering and Materials Science, Collaborative Innovation Center of Suzhou Nano Science and Technology, Soochow University, Suzhou, 215123, China.

\section{Corresponding Author}

*Jianmei Lu. E-mail: lujm@suda.edu.cn.

*Dongyun Chen. E-mail: dychen@suda.edu.cn. 


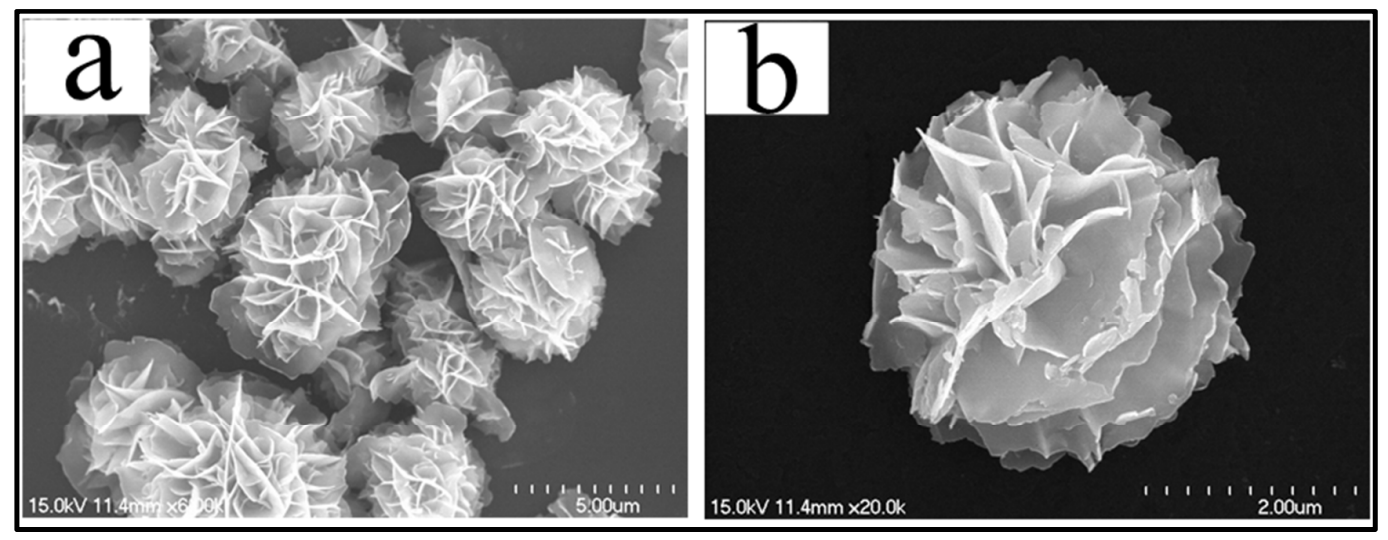

Figure S1. (a) Low and (b) high magnification SEM images of pure $\mathrm{SnS}_{2}$

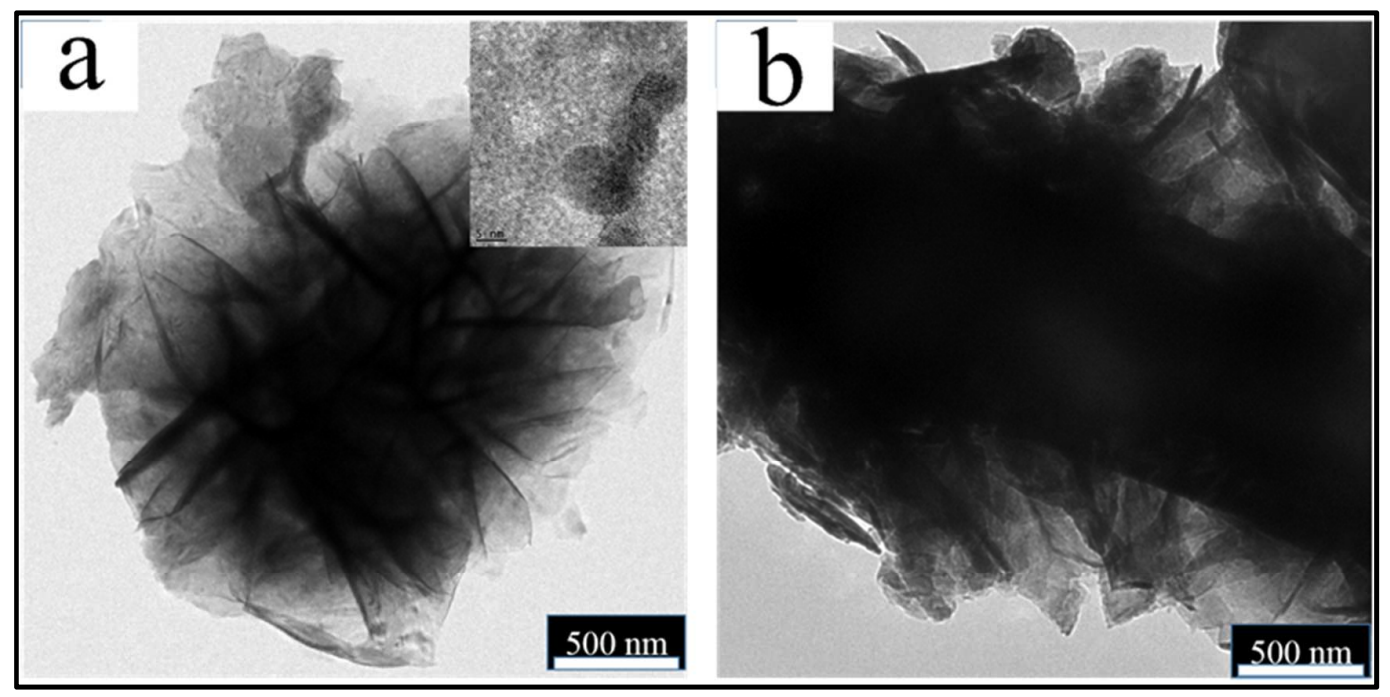

Figure S2.TEM images of pure $\mathrm{SnS}_{2} \mathrm{a}$ ) and $\mathrm{CNF} @ \mathrm{SnS}_{2}$ hybrid membranes b). 


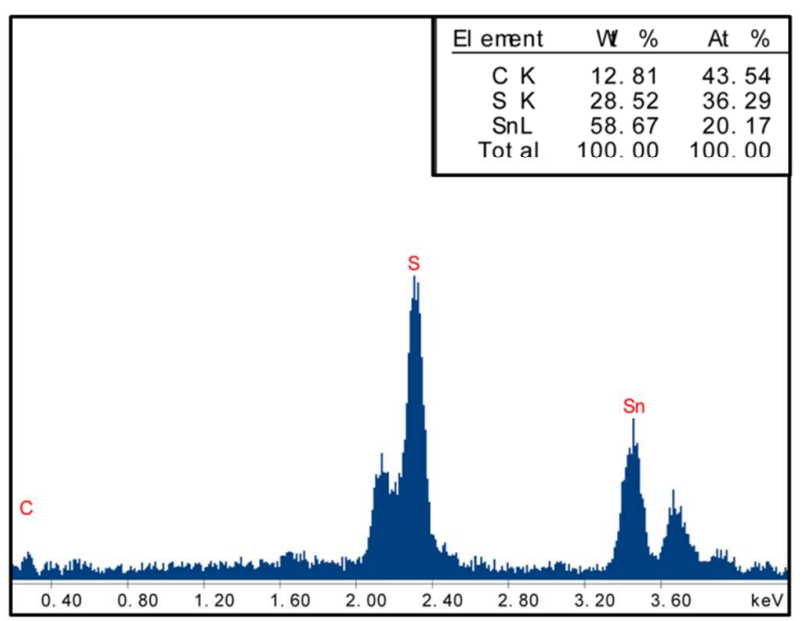

Figure S3.SEM-EDX of CNF@ $\mathrm{SnS}_{2}$ hybrid membranes.
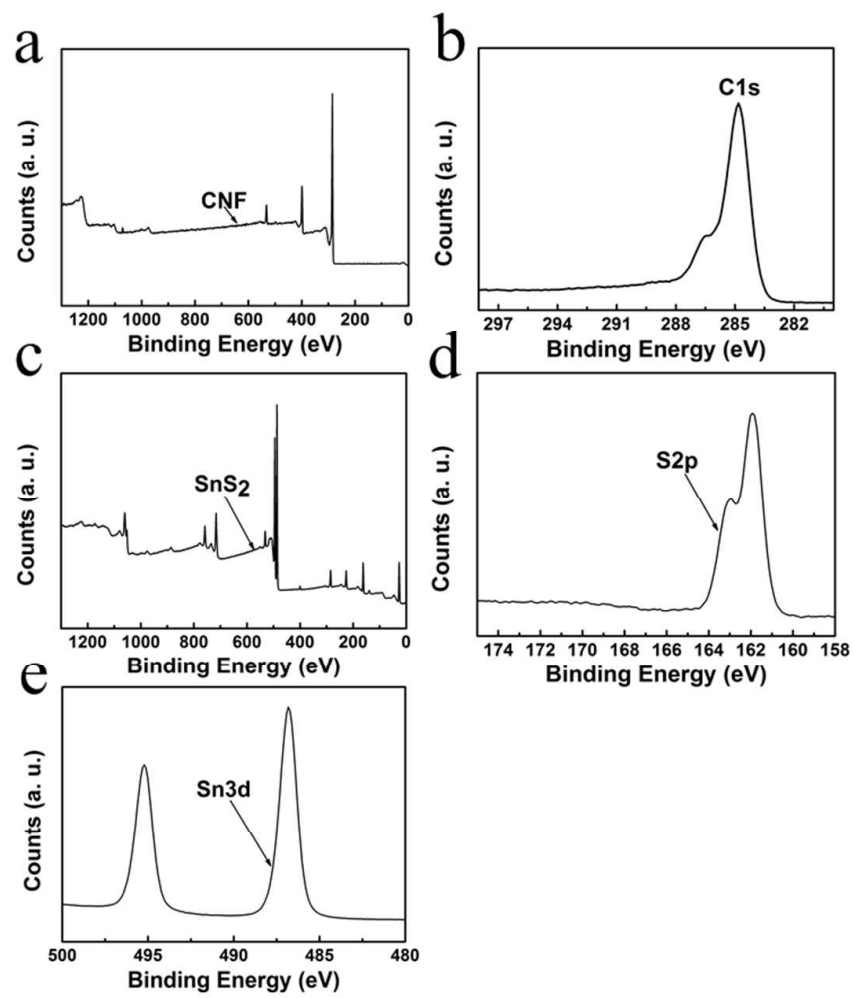

Figure S4.XPS survey spectrum a); C1s spectrum b) of the CNF membrane; XPS survey spectrum c); S 2p spectrum d); Sn 3d spectrum e) of theSnS $\mathrm{S}_{2}$ nanoparticles. 